\title{
Beden Eğitimi ve Spor Yüksek Okulu Öğrencilerinin Bazı Değișkenlere Göre Yalnızlık Düzeylerinin İncelenmesi
}

\author{
Servet REYHAN *
}

\begin{abstract}
Özet
Bu çalışmada, algılanan refah seviyesi ve bazı değişkenler kapsamında Beden Eğitimi ve Spor Yüksek Okulu öğrencilerinin yalnızlık düzeylerinin araştırılması amaçlanmıştır. Betimsel araştırma modelindeki çalışmanın örneklem grubunu Siirt Üniversitesi Beden Eğitimi ve Spor Yüksekokulu'nda farklı bölümlerde (Öğretmenlik, Antrenörlük ve Spor Yöneticiliği) öğrenim görmekte olan yaş aralığı 17-30 yaş olan toplamda 600 (326 Kadın, 274 Erkek) öğrenci oluşturmaktadır. Araştırmada,veri toplama aracı olarak kişisel bilgi formu ve "Yalnızlık Ölçeği” kullanılmıştır. Verilerin analizinde betimsel istatistikler ve güvenirlik analizlerinin yanı sıra, bağımsız gruplar t-testi, tek yönlü varyans analizi One-Way ANOVA ve pearson korelasyon analizinden yararlanılmıştır.

Cinsiyet ve yaş değişkeni kapsamında incelenen yalnızlık düzeyi Beden Eğitimi ve Spor Yüksek Okulu öğrencileri örnekleminde istatistiki açıdan anlamlı bir farka işaret etmemiş̧tir. Korelasyon analizi sonucunda katılımcıların yalnızlık düzeylerinin algılanan refah seviyesi ve algılanan boş zaman yeterliliği ile negatif yönlü bir ilişkisi olduğu sonucuna ulaşılmış ve yalnızlık ile algılanan refah seviyesi arasında istatistiki olarak anlamlı fark tespit edilmiştir $(\mathrm{r}=-0.175 \mathrm{p}<0.01)$.

Beden Eğitimi ve Spor Yüksek Okulu öğrencilerinin yalnızlık düzeylerinin incelendiği bu çalışmanın sonuçları, cinsiyet ve yaş değişkeni kapsamında özelliğin farklılaşmadığını ancak algılanan refah seviyesi ile yalnızlık düzeyinin negatif yönlü anlamlı bir ilişkisi olduğunu göstermiştir.
\end{abstract}

Anahtar Kelimeler: Yalnızlı, Refah Düzeyi, Beden Ĕ̈itimi ve Spor Öğrencileri

\section{Investigation of Levels of Loneliness According to Some Variables of School of Physical Education and Sports Students}

\begin{abstract}
In this study, it was aimed to investigate the loneliness levels of students within the scope of perceived welfare level. The sample group of the study in the descriptive research model consisted of 600 (326 Female, 274 Male) individuals aged between 17 and 30 who were studying in different departments. In the study, Loneliness Scale was used. In the data analysis, independent groups t-test, one-way analysis of variance OneWay ANOVA and pearson correlation analysis were used as well as descriptive statistics and reliability analysis.

The level of loneliness examined within the scope of gender and age variable did not indicate a statistically significant difference in the sample of students. As a result of the correlation analysis, it was concluded that the loneliness levels of the participants had a negative relationship with perceived welfare level and perceived leisure time adequacy and a statistically significant difference was found between loneliness and perceived welfare level. $(r=-0.175 \mathrm{p}<0.01)$.

Although the loneliness levels of the individuals who spend most of their time with sports activities are low, the welfare level perceived in the society is a factor that affects this characteristic.
\end{abstract}

Keywords - Loneliness, Welfare, Physical Education and Sports Students

* Dr. Öğretim Üyesi, Siirt Üniversitesi, Beden Eğitimi ve Spor Yüksekokulu, Siirt/Türkiye, serreyhannn@ gmail.com 


\section{GİRIŞ}

Sosyal bir varlık olan insan çevresi ile etkileşimi sonucu bazı gereksinimlerini gidermektedir. $\mathrm{Bu}$ ihtiyaçların fiziksel olanlarının yanı sıra duygusal da bir takım gereksinimlerden söz etmek mümkündür. Bu etkileşim sonucu birey ihtiyaçlarını karş1layarak kişisel yönünü geliştirmekte ve toplumda kendine belirlenen rolü üstlenebilmektedir.

Bireyler hızla değişim gösteren dünyada kendilerini etkileyen yalnızlık birçok faktörle karşılaşabilmekte (Stein \& Tuval-Mashiach, 2015) ve bu duygularla başa çıkmak için her türlü çabayı göstermektedirler (Reichmann, 1959). Ancak dünya düzenindeki bu hızlı değişim süreci bireyleri birbirinden uzaklaştırmakta ve dolayısıyla ilişkilerde zayıflıklar meydana gelmekte ve doğal olarak duygusal çöküntüler yaşanmakta ve birey kendini yalnız hissedebilmektedir (Jones, 1981; Reichmann, 1959; Weiss, 1973). Bunlarla birlikte özgüven eksiklikleri, boşanma, yakın kaybı, sosyal beceri yoksunluğu, sorunlarla baş edememe, sosyal destek eksikliği gibi pek çok faktörün birbirlerini harekete geçirmesi de katılımcıların yalnızlık hissetmesine yol açabilmektedir (Andersson, 1998; Bowman, 1955; Lee \& Ishii-Kuntz, 1987). Yalnız katılımcıların daha içe dönük, kaygıll, depresif olma eğilimi gösterdikleri, kendileri ve başkalarıyla ilgili olumsuz duygulara sahip oldukları (Levin ve Stokes, 1986), kendilerini karamsar, kötümser, kayg1l hissedip, atılgan hissetmedikleri (Lim, Rodebaugh, Zyphur \& Gleeson, 2016) sonucuna ulaşılmıştır. Ayrıca yalnız bireylerde düşük düzeyde psikolojik sağlamlık olduğunu gösteren araştırma sonuçlarının bulunduğu ifade edilmektedir (Güloğlu ve Kararrmak, 2010).

Yalnızlık, çağın getirdiği zorlu şartlarla daha belirgin bir sorun olarak ortaya çıkmakta ve insanlığın önünde büyük bir tehlike olarak durmaktadır. Gelişen teknoloji ve medeniyet dünyasıyla birlikte insanlar yaşam hızına ayak uydurmakta zorluk çekmekte, sosyal ilişkileri sinırlamakta, birbirlerine güvenmemekte, yabancılaşmakta ve mümkün olduğu kadar yüzeysel ilişkiler kurmaktadır. Modern dünya insanın yaşadığı tüm bu problemler, onu zorlamakta ailesel, sosyal yaşantı ve iş yaşamı da dâhil olmak üzere onu yalnızlaştırmaktadır (Alkan ve Sezgin, 1998). Yalnızlık, birey olmanın getirdiği risklerden bir tanesidir. Her yaş ve dönemde insan bu duyguyla karşılaşabilmektedir. Bireyin herkes tarafından kabul edilen ihtiyaçlarından bazıları da sevilme, ilgi görme gibi bireyin kendisi dışındaki insanlar tarafından doyurulabilecek ihtiyaçlardır. Birey için bu ihtiyaçların karşılanmaması ya da engellenmesi bireyi huzursuz etmekte, yalnızlık duygusunu ortaya çıkarmaktadır (Mellor, Stokes, Firth, Hayashi, \& Cummins, 2008).

Bireyin var olan sosyal ilişkisi ile ulaşmak istediği sosyal ilişkisi arasındaki tutarsızlık sonucu oluşan yalnızlık, öznel bir psikolojik durumdur (Jones, 1981; Reichmann, 1959; Weiss, 1973). İnsanlar yaşamlarının belli dönemlerinde yalnız kalabilirliler ya da yalnızlık duygusu yaşayabilirler. Birey kimi zaman kalabalıklar içerisinde bile yalnızlık yaşayabilir. Yalnızlık duygusu; kişiler arası ilişkilerin sosyal ihtiyaçları karşılamadığı, kişisel ihtiyaçları doyurmayı başaramadığı ve sosyal ödüllerin azaldığ 1 durumlarda ortaya çıkar. Yalnızlık sadece fiziksel olarak yalnız olma durumundan doğan bir duygu değildir (Russell, Cutrona, McRae ve Gomez, 2012). Yalnızlık pek çok faktörden etkilenmesine karşın temelinde, sosyal ilişkilerin yetersizliği ve bu ilişkilerden alınan doyum düzeyinin düşüklüğü bulunmaktadır (Buluş, 1997; Duru, 2008; Oktan, 2015).

Yalnızlık ile ilgili yapılan araştırmalar yalnızlığın birçok olumsuz sonucunun olduğunu göstermektedir. Yalnız kişiler yalnız olmayanlara göre sağlık hizmetlerine daha çok ihtiyaç duymaktadırlar. Yalnızlığın, yaşla birlikte fizyolojik düşüş oranını hızlandırdığı, yaşlanmayı hızlandırdığı, bunama riskini arttırdığı ayrıca zaman içinde tüm bilişsel yetileri zayıflattığ \& Patrick, 2008). Yapılan çalışmalarda yalnızlık yaşayan katılımcıların olumsuz düşüncelerinin sadece kendilerine yönelik olmadığı da göze çarpmaktadır (Rottenberg, 1994). Davis ve Franzoi (1986) yaptıkları çalışmada, yalnızlık hisseden katılımcıların yakın arkadaşlarına dahi güvensiz oldukları ve onlarında kendileri için böyle düşündüklerine inandıklarını vurgulamışlardır. Yalnızlık 
yaşayan bireylerle yapılan bu çalışmalar göz önünde bulundurulduğunda yalnızlık yaşayan katılımcıların biliş ve inanışlarında çarpıklık ya da çarpıtmaların var olduğu ya da geliştiği söylenebilir. Bilişsel çarpitmalara benzer şekilde Mahoney (1999) ise yabancılaşmak ve gerçekçi olmayan inançlar arasında anlamlı bir ilişkiyi vurgularken literatürü destekler şekilde Halamandaris ve Power (1997)'de yalnızlık düzeyi ve sahip olunan işlevsel olmayan tutumlar arasında ilişki tespit etmiştir. Yalnızlık duygusunun yarattığı psikolojik olumsuzluklardan kurtulmak isteyen birey spora yönleniyor.

Bireyi spora yönlendiren psikolojik gereksinimlere bakıldığında, toplumda bir yer edinme kaygısı, başkaları tarafından tanınma gereksinimi, yokluğu hissedilen bir kişi olma gibi özellikler dikkat çekmektedir (Singer, Hausenblas \& Janelle, 2001). Bu ihtiyaçlar hiyerarşisinde özellikle genç bireylerde sosyal gereksinimlerin büyük rol oynadığ 1 belirtilmektedir (Baumann, 1994). Spor, bireylerle yakın ilişkilerin kurulduğu önemli bir iletişim aracıdır. Bireye sosyal bir çevre kazandırabilen spor, bedene ve ruha hitap eden sosyal bir davranış olarak görülmektedir. Spor katılımcıların toplumsal bütünlüğünü sağlayan ve aynı zamanda katılımcıların ruhsal ve bedensel sağlıklarını güvence altına alan önemli bir olgu olarak bilinmekte ve bireyin sosyal hayatında etkili bir motif olarak görülmektedir (Balcıŏlu, 2003). Sağlık ve spor psikolojisi araştırmaları, fiziksel aktivitenin bireyin sosyal desteğinin gelişimini kolaylaştırabileceğini göstermektedir. Fiziksel aktivite esnasında kurulan sosyal etkileşimler, bireyin sosyal destek algisinı etkileyebilmektedir (Sheridan, Coffee, \& Lavallee, 2014).

$\mathrm{Bu}$ bilgiler 1şı̆̆ında spor temelli eğitim alan beden eğitimi ve spor yüksekokulu öğrencilerinin yoğun eğitim-öğretim dönemlerinde yaşadıkları duygusal durumlar arasında yer alan yalnızlık süreçleri merak edilmektedir. Sporun, bireyin psikolojik gelişimine etki ettiği bilinmesine rağmen bazı durumlarda ve koşullarda bireyler bu süreçleri yönetmekte zorluk çekmektedir. Eğitim sürecide bu durumlardan bir tanesi olarak bilinmekte ve öğrencilerin bu süreçte karşılaşabilecekleri güçlüklerin psikolojik etkilerinin olduğu bilinmektedir. Dolayısıyla bu çalışmada beden eğitimi ve spor yüksekokulu öğrencilerinin bazı değişkenler eşliğinde yalnızlık düzeylerinin incelenmesi amaçlanmıştır.

\section{Araştırmanın Amacı}

$\mathrm{Bu}$ çalışmada, algılanan refah seviyesi ve bazı değişkenler kapsamında BESYO öğrencilerinin yalnızlık düzeylerinin araştırılması amaçlanmıştır.

\section{YÖNTEM}

\section{Çalışma Grubu}

Betimsel araştırma modelindeki çalışmanın örneklem grubunu Siirt Üniversitesi Beden Eğitimi ve Spor Yüksekokulu'nda farklı bölümlerde (Öğretmenlik, Antrenörlük ve Spor Yöneticiliği) öğrenim görmekte olan yaş aralı̆̆1 $17-30$ yaş olan toplamda 600 (326 Kadın, 274 Erkek) katılımcı oluşturmaktadır.

\section{Veri Toplama Araçları}

Çalışmanın hipotezlerini test etmek amacıyla oluşturulan form iki kısımdan oluşmaktadır. Birinci bölümde katılımcıların demografik bilgilerinin yer aldığı kişisel bilgi formu ikinci kısımda ise "UCLA Yalnızlık Ölçeği (University of California Los Angeles Loneliness Scale-UCLA-YÖ)" kullanılmıştır (Russell, Peplau ve Ferguson, 1978; Türkçe Uyarlama Demir, 1989). Kişisel bilgi formunda katılımcıların toplum içerisinde algıladıkları refah durumlarını 1'den 4'e (Kötü-Normal-Iyi-Çok iyi) kadar derecelendirmeleri istenmiştir. Ayrıca haftalık boş zamanlarının yeterli olup olmadığını belirten soruya ise 1'den 5'e (Kesinlikle Yetersiz-Yetersiz-Normal-Yeterli-Kesinlikle Yeterli) kadar derecelendirme istenmiştir. Araştırma kapsamında kullanılan UCLA-YÖ 4'lü likert tipinde derecelendirilen bir ölçme arac1 olup, tek boyut ve 20 maddeden oluşmaktadır. Ölçekte yer alan maddelerin 10 tanesi olumsuz ifadelerden oluşmakta ve bu maddeler analiz esnasında ters çevrilmektedir. Ölçekten alınan yüksek puan yüksek yalnızlık düzeyine, düşük puan düşük yalnızlık düzeyine işaret etmektedir. Ayrıca elde edilen sürekli 
Reyhan, S. / Beden Eğitimi ve Spor Yüksek Okulu Öğrencilerinin Bazı Değişkenlere Göre Yalnızlık Düzeylerinin İncelenmesi

puanlar sinıflandırılarak; 20-34 arasındaki puanlar düşük, 35- 48 arasındaki puanlar orta, 49 ve üstündeki puanlar yüksek derecede yalnızlık olarak değerlendirilmektedir. Demir, A. (1989)

\section{Verilerin Analizi}

Analizler öncesinde verinin normal dağılıp dağılmadığı kontrol edilmiş ve KolmogorowSmirnov normallik testi sonucunda verinin normallik varsayımını karşıladığ 1 belirlenmiştir ( $>>0,05)$. İkili karşılaştırmaların tespiti için TTesti, ikiden fazla bağımsız değişkenler ile bağımlı değişkenler arasındaki farkın tespiti için ANOVA testi kullanılmıştır. İkiden fazla bağımsız değişkenler ile bağımlı değişkenler arasındaki farkın anlamlılığına ilişkin POSTHOC testlerinden TUKEY testi kullanılmıştır.“ UCLA Yalnızlık Ölçeği” ölçeği alt boyutları arasındaki ilişkinin tespiti için de pearson korelasyon analizi kullanılmıştır.

\section{BULGULAR}

Tablo 1: Cinsiyet Değişkenine Göre Katılımcıların Yalnızlık Düzeylerinin Karşılaştırılması

\begin{tabular}{cccccccc}
\hline \multirow{3}{*}{ Yalnızlık } & \multicolumn{1}{c}{$\mathrm{N}$} & $\bar{x}$ & $\mathrm{SS}$ & $\mathrm{df}$ & $\mathrm{t}$ & $\mathrm{p}$ \\
\cline { 2 - 7 } & Kadın & 326 & 2.03 & 0.42 & \multirow{2}{*}{598} & \multirow{2}{*}{0.020} & \multirow{2}{*}{0.98} \\
\cline { 2 - 6 } & Erkek & 274 & 2.03 & 0.44 & & \\
\hline
\end{tabular}

Tabloya 1'e göre Yalnızlık ölçeğinin cinsiyet değişkenine göre anlamlı farklılık görülmemiştir $\mathrm{P}>0,05$. Katılımcıların puan ortalamaları dikkate alındığında orta düzeyde bir yalnızlık düzeyine sahip oldukları anlaşılmaktadır.

Tablo 2: Yaş Değişkenine Göre Katılımcıların Yalnızlık Puan Ortalamalarına İlişkin ANOVA Sonuçları

\begin{tabular}{|c|c|c|c|c|c|c|c|c|c|c|c|}
\hline & Yaş & $\mathbf{N}$ & $\bar{x}$ & SS & $\begin{array}{l}\text { Varyans } \\
\text { Kaynağı }\end{array}$ & $\begin{array}{l}\text { Kareler } \\
\text { toplamı }\end{array}$ & Sd & $\begin{array}{c}\text { Kareler } \\
\text { ortalama } \\
\text { sı }\end{array}$ & $\mathbf{F}$ & $\mathbf{p}$ & $\begin{array}{c}\text { Anlamlı } \\
\text { Fark }\end{array}$ \\
\hline \multirow{3}{*}{ 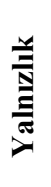 } & 17-20 Yaş & 175 & 2.08 & 0.41 & \multirow{2}{*}{$\begin{array}{c}\text { Gruplar } \\
\text { arası }\end{array}$} & \multirow{2}{*}{0.67} & \multirow{2}{*}{3} & \multirow{2}{*}{0.33} & \multirow{3}{*}{1.805} & \multirow{3}{*}{0.165} & \multirow{3}{*}{-} \\
\hline & $21-25$ Yaş & 380 & 2.01 & 0.44 & & & & & & & \\
\hline & 26-30 Yaş & 45 & 2.00 & 0.40 & $\begin{array}{l}\text { Grup } \\
\text { içi }\end{array}$ & 110.23 & 446 & 0.19 & & & \\
\hline
\end{tabular}

Tablo 2'ye göre, analiz sonuçları, katılımcıların yalnızlık ölçeğinin alt boyutlarının sınıf değişkenine göre anlamlı farklılık göstermemediği tespit edilmiştir ( $>0,05)$.

Tablo 3: Algılanan Refah Seviyesi, Algılanan Boş Zaman Yeterliliği ve Yalnızlık Değişkenlerine İlişkin Korelasyon Analizi Sonuçları

\begin{tabular}{ccccc}
\hline Değişken & Yalnızlık & $\begin{array}{c}\text { Algılanan } \\
\text { Refah Düzeyi }\end{array}$ & Ort. & ss \\
\hline Yalnızlık & - & & 2.03 & 0.43 \\
\hline Algılanan Refah Düzeyi & $-0.175^{* *}$ & - & 2.43 & 0.84 \\
\hline $\begin{array}{c}\text { Algılanan Boş Zaman } \\
\text { Yeterliliği }\end{array}$ & -0.053 & $0.091^{*}$ & 3.03 & 1.01 \\
\hline
\end{tabular}


Korelasyon analizi sonuçlarının yer aldığı Tablo 3 incelendiğinde katılımcıların yalnızlık düzeylerinin algılanan refah seviyesi ve algılanan boş zaman yeterliliği ile negatif yönlü ilişkilerinin olduğu görülmektedir. Toplumda algılanan refah seviyesi katılımcıların yalnızlık düzeyleri ile düşük düzeyde ( $\mathrm{r}=-0.175)$ negatif yönlü bir ilişkiye sahipken, katılımcıların algılanan boş zaman yeterliliği düşüncelerinin yalnızlık seviyeleri ile istatistiki açıdan anlamlı olmayan $(\mathrm{r}=-0.053)$ negatif yönlü bir ilişkisinin olduğu bulgulanmıştır. Dolayısıyla BESYO öğrencileri örnekleminde, katılımcıların toplumda algıladıkları refah seviyelerinin artması yalnızlık düzeylerindeki azalmaya sebep olduğu sonucuna ulaşılmıştır.

\section{TARTIŞMA ve SONUÇ}

Beden eğitimi ve spor yüksekokulu öğrencileri örnekleminde gerçekleştirilen bu çalışma bulguları, katılımcıların cinsiyet ve yaş değişkeni kapsamında yalnızlık düzeylerinde anlamlı farklılıkların olmadığını göstermiştir. Ayrıca katılımcıların boş zaman yeterlilikleri ile yalnızlık arasında anlamlı bir ilişki tespit edilemezken yalnızlığın katılımcıların toplumdaki refah düzeyi algıları ile düşük düzeyde negatif yönlü bir ilişkisi olduğu tespit edilmiştir.

Katılımcıların yalnızlık ölçeğinden aldıkları puan ortalamaları dikkate alındığında orta düzey bir yalnızlık duygusundan söz edilebilir (ort=2.03). Literatür incelendiğinde benzer sonuçlar dikkat çekmektedir (Arkar, Sarı, ve Fidaner, 2004; Buluş, 1997; YazıcılarÖzçelik, İmamoğlu, Çekin, ve GölünükBaşpınar, 2015; Yılmaz, Yılmaz ve Karaca, 2008). Desteklenen bu sonuçlar eşliğinde beden eğitimi ve spor yüksekokulu öğrencilerinin ortalama yalnızlık duygusuna sahip olduğu ve eğitimlerinin temelinde yer alan spor olgusunun bireyler arasinda duygusal durumlarda anlamlı değişimleri ortadan kaldırdığı sonucuna ulaşılmıştır. Diğer katılımcılar gibi beden eğitimi ve spor yüksekokulu öğrencilerinin de çevresel etkiler sebebi ile bu yalnızlık düzeyine sahip olduğu düşünülmektedir.

Araştırmanın cinsiyet değişkeni bulguları incelendiğinde bireyler arasında anlaml farklılığın olmadığı dikkat çekmektedir. Kadın ve erkek katılımcıların aynı ortalamaya sahip olduğu ve yalnızlık düzeylerinin ortalama seviyede olduğu izlenmiştir. Araştırma bulgularını doğrular nitelikte sonuçlara ulaşılmıştır (Eskin, 2001; Kozaklı,
2006; Y1lmaz, Y1lmaz ve Karaca, 2008). İlgili literatürde araştırma sonuçlarının aksine kadınlar ve erkekler arasında yalnızlık bağlamında istatistiki açıdan anlamlı farklılıklar da tespit edilmiştir (Cramer \& Neyedley, 1998). Cinsiyet değişkeni kapsamında farklı sonuçların bulgulandığı yalnızlık özelliği beden eğitimi ve spor yüksekokulu öğrencilerinde anlamlı bir değişime yol açmamıştır. Her türlü spor branşını hem erkek katılımcıların hem de kadın katılımcıların yapabildiği göz önüne alındığında bu eğitim kurumundaki katılımcıların yalnızlık düzeylerindeki anlamlı farklılığın belirmeme durumu, spor faktörünün her iki gruba da aynı düzeyde yakın olmasından kaynaklandığı düşünülmektedir.

Araştırmanın bir diğer parametresi olan yaş değişkeni sonuçlarına bakıldığında, farklı yaş gruplarından katılımcıların ortalama yalnızlık düzeyine sahip oldukları ve bu durumun katılımcilar arasinda anlamlı bir farka yol açmadığ 1 sonucu belirlenmiştir. Literatürde yalnızlıkla ilgili yapılan çalışmalar incelendiğinde çalışma bulgularına paralellik gösteren sonuçlar tespit edilmiştir (Le Roux, 2001; Yılmaz, Y1lmaz ve Karaca, 2008). Yapılan bazı çalışmalarda ise yaş değişkeninin yalnızlık ile negatif yönlü bir ilişkisi olduğu ve yaşın artması ile birlikte yalnızlık düzeyinin azaldığ (Kozakl1, 2006; Orzeck \& Rokach, 2004). Beden eğitimi ve spor yüksekokulu öğrencilerinden oluşan katılımcıların bu sonucu, ortalama aynı yaş düzeyine sahip oldukları ve birbirine benzer psikolojik süreçler yaşadıkları, benzer çevresel etmenlere maruz kaldıkları ve aynı sosyal 
çevreden faydalandıkları dolayısıyla bu nedenle aralarında anlamlı farkın belirmediği şeklinde yorumlanmıştır.

Katılımcıların algıladıkları refah düzeyleri ile boş zaman yeterliliklerinin yalnızlık düzeyleri ile ilişkisinin incelendiği çalışma verileri, toplumda algilanan refah düzeyinin yalnızlıkla negatif yönlü bir ilişkisinin olduğunu gösterirken, boş zaman yeterliliği ile yalnızlık düzeyinin istatistiki açıdan ilişkisinin olmadığını göstermiştir. $\mathrm{Bu}$ bulgudan yola çıkarak toplumda algılanan refah seviyesinin artmasının bireylerdeki yalnızlık düzeyini düşürdüğü sonucuna ulaş1labilmektedir. Çalışma bulgularına birebir benzeyen araştırmalara rastlanmamıştır. Ancak konu kapsamında değerlendirilen literatürde ilgili özelliklere ilişkin görüşler belirlenmiştir. Aytaç (2002) boş zaman kavramını değerlendirdiği çalışmasında toplumdaki refah seviyesindeki artışın katılımcıların boş zamanlarında da artışa yol açabileceğine vurgu yapmıştır. Bu tahminden yola çıkarak katılımcıların refah düzeylerindeki artışla birlikte oluşabilecek boş zaman yeterliliğinin, bireyleri farklı aktivite kanallarına yönlendirebileceği ve böylece sosyal iletişimlerin artması ile birlikte yalnızlık seviyesinde azalma meydana gelebileceği düşünülmektedir.

Beden eğitimi ve spor yüksekokulu öğrencileri örnekleminde gerçekleştirilen bu çalışmanın sonuçları, cinsiyet ve yaş değişkeninin katılımcıların yalnızlık düzeyinde anlamlı bir farka yol açmadığ 1 ancak toplumda algılanan refah düzeyinin katılımcıların yalnızlık düzeyleri ile negatif yönlü ilişkisi olduğunu göstermiştir. Hızla değişim gösteren dünyada toplumlarda artan refah düzeyinin birçok psikolojik özelliğe iyi gelebildiği ve yalnızlık da bu özellikler arasında yer aldığı görülmektedir. Farklı sosyolojik ve psikolojik özelliklerle yalnızlık kavramının detaylı olarak incelenmesi ve spor kavramının bu bağlamda ilişkisinin irdelenmesi önerilmektedir.

\section{KAYNAKÇA}

Alkan S, Sezgin A (1998) Yetişkin hastalarda yalnızlı. Cumhuriyet Üniversitesi
Hemşirelik Yüksekokulu Dergisi, 2(1): 43-52.

Andersson, L. (1998). Loneliness research and interventions: A review of theliterature. Aging\&mental health, 2(4), 264-274.

Arkar, H., Sarı, Ö. ve Fidaner, H. (2004). Relation ships betweenquality of life, perceived social support, social network and loneliness in a Turkishsample. Yeni Symposium, 42: 20-7.

Balcıoğlu, İ. (2003). Sporun sosyolojisi ve psikolojisi. Bilge Yayınları: İstanbul.

Baumann, S. (1994). Uygulamall spor psikolojisi. (Çev: C. İkizler, O.A. Özcan), Alfa Basım Yayım Dağıtım: İstanbul.

Bowman, C. C. (1955). Loneliness and social change. American Journal of Psychiatry, 112(3), 194-198.

Buluş, M. (1997). Üniversite öğrencilerinde yalnızlık. Pamukkale Üniversitesi Eğitim Fakültesi Dergisi, 3(3), 82-90.

Cacioppo, J. T.,\&Patrick, B. (2008). Loneliness: Human nature and the need for social connection. Norton: New York, NY

Cramer, K. M.,\&Neyedley, K. A. (1998). Sex differences in loneliness: The role of masculinity and femininity. Sexroles, 38(7-8), 645-653.

Davis, M. H.,\&Franzoi, S. L. (1986). Adolescent loneliness, self-disclosure, and private self-consciousness: A longitudinal investigation. Journal of Personality and Social Psychology, 51(3), 595.

Demir, A. (1989). UCLA yalnızlık ölçeğinin geçerlik ve güvenirliği. Psikoloji dergisi, 7(23), 14-18.

Duru, E. (2008). Sosyal bağlılık ve sosyal desteğin yalnızlık üzerine doğrudan ve dolaylı rollerinin üniversiteye uyum süreci çerçevesinde incelenmesi. Türk Psikolojik Danısma ve Rehberlik Dergisi, 29(3), 1324.

Eroğlu, E. (2019). Türkiye'de Spor Yönetimi, Türkeri, C. (Ed). Beden eğitimi ve spor bilimlerinin temelleri. (ss. 91-103) Ankara. Akademisyen Yayınevi

Eskin, M. (2001). Ergenlikte yalnızlık, baş etme yöntemleri ve yalnızlığın intihar davranışı ile ilişkisi. Klinik Psikiyatri, 4:5-11. 
Güloğlu, B. ve Karairmak, Ö. (2010). Üniversite öğrencilerinde yalnızlığın yordayıcısı olarak benlik saygısı ve psikolojik sağlamlık. Ege Ĕ̈itim Dergisi, 11(2), 7388.

Halamandaris, K. F.,\&Power, K. G. (1997). Individual differences, dys functional attitudes, and social support: A study of the psychosocial adjustmentto university life of home students. Personality and Individual Differences, 22(1), 93-104.

Jones, W. H. (1981). Loneliness and socialcontact. The Journal of Social Psychology, 113(2), 295-296.

Kozaklı, H. (2006). Üniversite ögrencilerinde yalnızlık ve sosyal destek düzeyleri arasındaki ilişkilerin karsılaştırılması. Yüksek Lisans Tezi, Mersin Üniversitesi Sosyal Bilimler Enstitüsü, Mersin.

Le Roux, A. (2001). Connors J. A cross-cultural study into loneliness amongst university students South African Journal of Psychology, 31: 46.

Lee, G. R.,\&Ishii-Kuntz, M. (1987). Social interaction, loneliness, and emotional well-being among the elderly. Research on aging, 9(4), 459-482.

Levin, I.,\&Stokes, J. P. (1986). An examination of the relation of individual difference variables toloneliness. Journal of Personality, 54(4), 717-733.

Lim, M. H.,Rodebaugh, T. L., Zyphur, M. J., \&Gleeson, J. F. (2016). Loneliness over time: The crucial role of social anxiety. Journal of abnormal psychology, 125(5), 620.

Mahoney, J. M. (1999). A lienation and irrational lbeliefs in a nonclinical university population. Psychological reports, 84(1), 137-140.

Mellor, D.,Stokes, M., Firth, L., Hayashi, Y., \& Cummins, R. (2008). Need for belonging, relation ship satisfaction, loneliness, and life satisfaction. Personality and individual differences, 45(3), 213-218.

Oktan, V. (2015). Üniversite öğrencilerinde problemli internet kullanimi, yalnizlik ve algilanan sosyal destek. Kastamonu Eğitim Dergisi, 23(1), 281-292.

Orzeck, T.,\&Rokach, A. (2004). Men Who Abuse Drugs and Their Experience of Loneliness. European Psychologist, 9(3), 163.

Reichmann, F. F. (1959). Loneliness. Psychiatry, 22(1), 1-15.

Rotenberg, K. J. (1994). Loneliness and interpersonall trust. Journal of Social and Clinical Psychology, 13(2), 152-173.
Russell, D. W.,Cutrona, C. E., McRae, C., \& Gomez, M. (2012). Is loneliness the same as beinga lone?.The Journal of psychology, 146(1-2), 7-22.

Russell, D.,Peplau, L. A., \& Ferguson, M. L. (1978). Developing a measure of loneliness. Journal of personality assessment, 42(3), 290-294.

Sheridan, D.,Coffee, P., \& Lavallee, D. (2014). A systematic review of social support in youth sport. International Review of Sport and Exercise Psychology, 7(1), 198-228.

Singer, R. N.,Hausenblas, H. A., \& Janelle, C. M. (2001). Hand book of sport psychology. John Wiley\&SonsInc.

Stein, J. Y.,\& Tuval-Mashiach, R. (2015). The social construction of loneliness: An integrative conceptualization. Journal of Constructivist Psychology,28(3), 210227.

Weiss, R. S. (1973). Loneliness: The experience of emotional and socialisolation. Cambridge, MA: MIT Press

Yavuz Eroğlu, S. (2019). Spor yönetimi yapıs1, Türkeri, C. (Ed). Beden eğitimi ve spor bilimlerinin temelleri. (ss. 91-103) Ankara. Akademisyen Yayınevi

Yavuz Eroğlu, S., Karakuş, S \& Işık, U. (2016). Türk spor politikasında güncel sorunların incelenmesi. Türk \& Íslam Dünyast Araştırmaları Dergisi. 3(9). 186-201

Yazıcılar-Özçelik, İ., İmamoğlu, O., Çekin, R. ve Gölünük-Başpınar, S. (2015). Üniversite öğrencilerinin yalnızlık düzeyleri üzerine sporun etkisi. Spor ve Performans Araştırmaları Dergisi, 6 (1), 12-18.

Y1lmaz, E., Y1lmaz, E., \& Karaca, F. (2008). Üniversite öğrencilerinin sosyal destek ve yalnızlık düzeylerinin incelenmesi. Genel Tip Dergisi, 18(2) 